\title{
Double lumen esophagus due to false submucosal path induced by nasogastric tube: endoscopic treatment with marsupialization
}

A 39-year-old man with a medical history of vertebrobasilar stroke 1 year previously, associated with tobacco and cocaine use, presented with dysphagia. During his hospitalization, the patient developed swallowing disorders. An attempt to insert a nasogastric tube (NGT) was unsuccessful owing to unusual resistance. A percutaneous endoscopic gastrostomy was therefore performed. During upper gastrointestinal endoscopy (UGE), a false submucosal path, secondary to NGT impaction was observed, with upper and lower orifices located at $33 \mathrm{~cm}$ and $38 \mathrm{~cm}$, respectively, from the dental arches ( $\mathbf{F i g . 1}$ ). Enteral nutrition and proton pump inhibitors were initiated but no endoscopic surveillance was proposed.

One year later, when the patient restarted oral intake, he started describing episodes of dysphagia, especially with solid food. A UGE was performed and esophageal duplication was observed, corresponding to a chronicization of the false submucosal path, which partially obstructed the esophagus, especially by inducing food impaction (-Fig.2). A guidewire (Jagwire; Boston Scientific, Marlborough, Massachusetts, USA) was advanced from the upper toward the lower orifice to confirm the permeability of the false path (> Fig. 3 ). Then, an antegrade complete incision of the submucosal flap was performed, initially using an ITknife nano (Olympus, Tokyo, Japan) to secure the cut. However, the knife was quickly switched to a $2 \mathrm{~mm}$ Dualknife (Olympus) because of difficulties in current application. The incision was carried out from the proximal to the distal orifice, following the guidewire, without any complication ( Video 1 ). Immediately following this marsupialization approach, the patient had no further dysphagia.

At follow-up 6 months later, the patient reported gastroesophageal reflux without dysphagia. Endoscopy revealed ulcerated esophagitis and a pseudodiverticu-

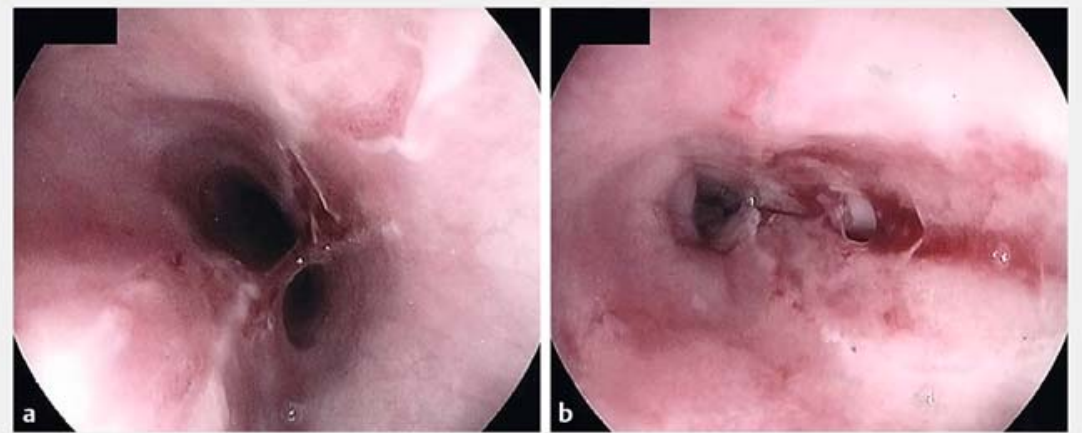

Fig. 1 False submucosal path induced by the nasogastric tube. a Upper orifice $(33 \mathrm{~cm}$ from the dental arch). $\mathbf{b}$ Lower orifice ( $38 \mathrm{~cm}$ from the dental arch).

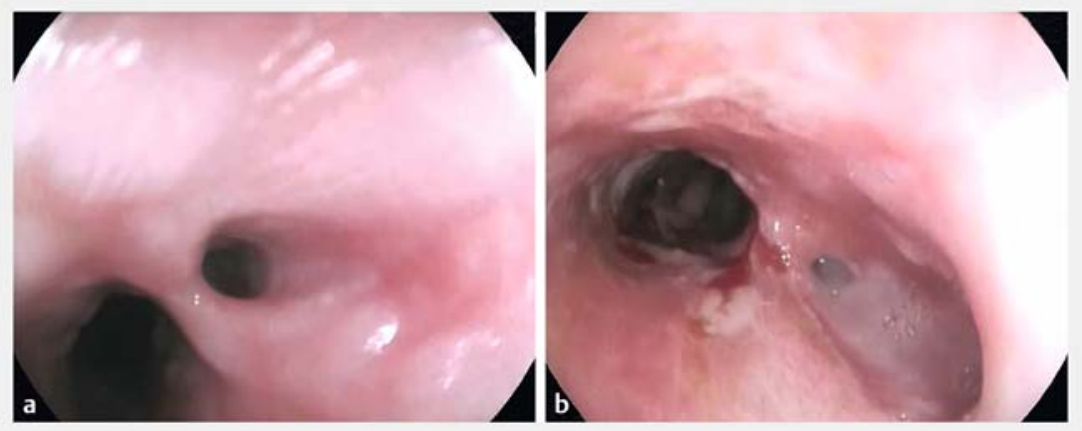

Fig. 2 One year later: chronicization of the false submucosal path. a Upper orifice $(33 \mathrm{~cm}$ from the dental arch). b Lower orifice ( $38 \mathrm{~cm}$ from the dental $\mathrm{arch}$ ).

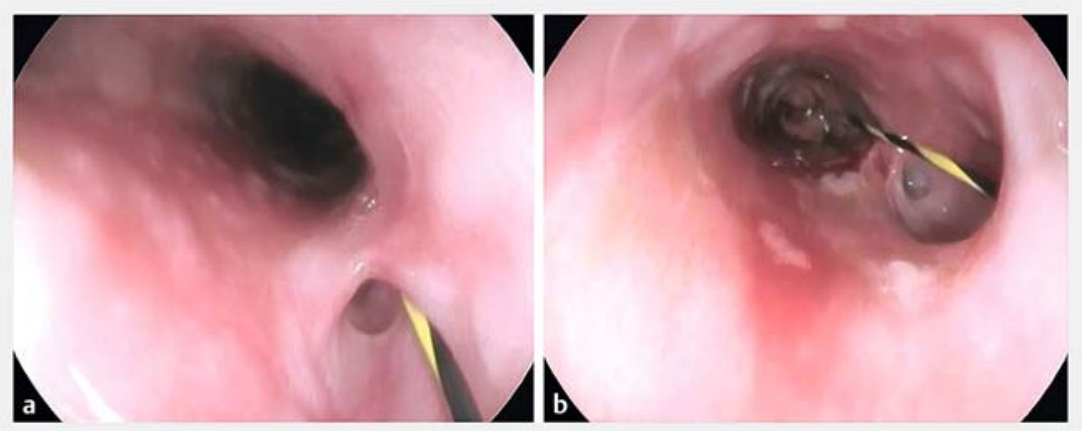

Fig. 3 Guidewire in the false path. a Upper orifice ( $33 \mathrm{~cm}$ from the dental arch). b Lower orifice $(38 \mathrm{~cm}$ from the dental arch). 


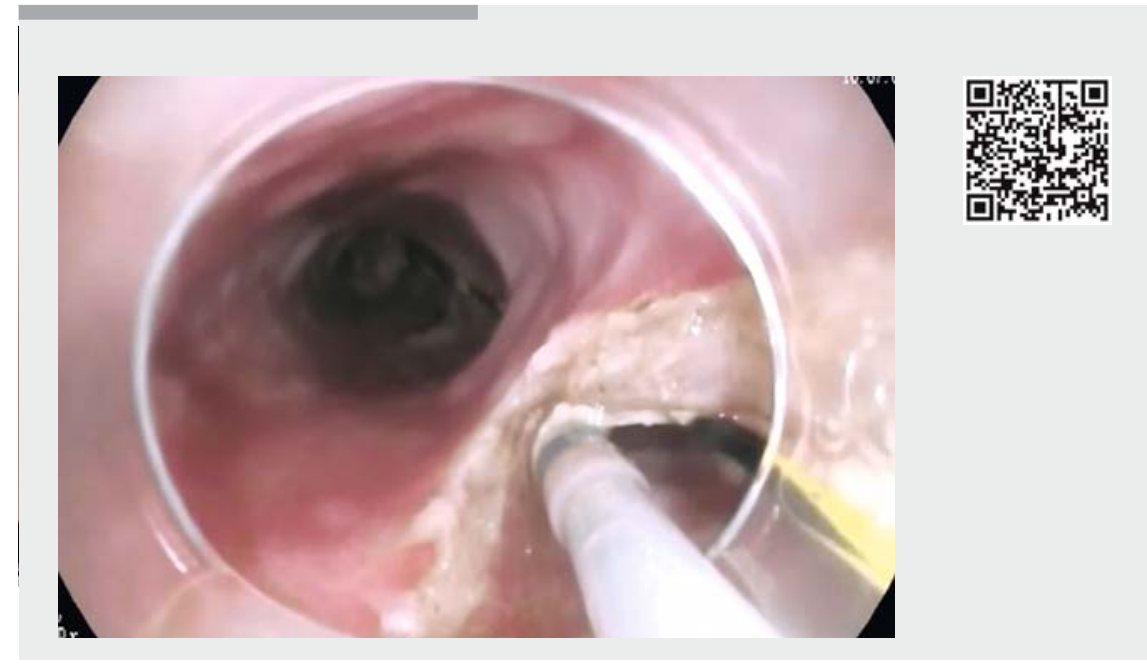

$\checkmark$ Video 1 Endoscopic treatment with marsupialization for double lumen esophagus caused by nasogastric tube. a Proximal orifice. b Distal orifice.

lum just above the esophagogastric junction, corresponding to the inferior site of NGT impaction, but without significant stenosis.

In conclusion, the double lumen esophagus secondary to NGT impaction is a rare complication, with only two other cases found in the literature [1,2]. We describe here the first case of successful endoscopic treatment by marsupialization.

Endoscopy_UCTN_Code_CPL_1AH_2AG

\section{Competing interests}

None

The authors

Jean-Philippe Le Mouel'1 , Paul Basile², JeanMichel Gonzalez ${ }^{3}$, Rodrigo Irarrazaval ${ }^{4}$,

Mélanie Serrero ${ }^{3}$, Marc Barthet ${ }^{3}$

1 Department of Gastroenterology, Amiens University Hospital, Amiens, France

2 Department of Gastroenterology, Rouen University Hospital, Rouen, France

3 Department of Gastroenterology, Marseille University Hospital, Marseille, France

4 Department of Gastroenterology, Clinic Davila, Metropolitan Region, Santiago, Chile

Corresponding author

Jean-Philippe Le Mouel, MD

\section{References}

[1] Yang CW, Yen HH, Su WW et al. Esophageal submucosal tunnel: a rare complication of nasogastric tube placement. Dis Esophagus 2016; 29: 690

[2] Tashiro M, Matsuda K, Ueda R. Double lumen esophagus: a rare complication of nasogastric tube? Dig Endosc 2014; 26: 680

\section{Bibliography}

DOI https://doi.org/10.1055/a-0667-7648

Published online: 5.9.2018

Endoscopy 2018; 50: E325-E326

(c) Georg Thieme Verlag KG

Stuttgart · New York

ISSN 0013-726X

\section{ENDOSCOPY E-VIDEOS \\ https://eref.thieme.de/e-videos}

Department of Gastroenterology, Amiens University Hospital, Amiens Picardie 80054, France

Fax: +33-322-668947

jeanphilippe.lemouel@wanadoo.fr 